Ethiopian Journal of Environmental Studies \& Management 7 Suppl.: 821 - 831, 2014.

ISSN:1998-0507

doi: http://dx.doi.org/10.4314/ejesm.v7i2.2S

Submitted: September 15, 2014

Accepted: November 17, 2014

\title{
ANALYSIS OF CLIMATE CHANGE SIGNATURES ON MICRO-CATCHMENTS AS A MEANS OF UNDERSTANDING DRYING UP OF WETLANDS: THE CASE OF MUTUBUKI WETLAND IN GUTU DISTRICT OF ZIMBABWE
}

*CHIKODZI, D. AND MUTOWO, G.

Great Zimbabwe University, Department of Physics, Geography and Environmental Science,

P.O Box 1235, Masvingo, Zimbabwe

\begin{abstract}
Wetlands are one of the most vulnerable ecosystems to climate change, over use and degradation. The research was aimed at investigating the impacts of climate variability on wetlands. Specifically, this paper was aimed at determining whether trends in the patterns of rainfall and temperature can be used to explain the drying up of Mutubuki wetland in Gutu District of Zimbabwe. Research methodology adopted involved analysis of time series rainfall and temperature data from the nearby Alheit Mission, as well as rainfall data from Buhera and Chivhu weather stations located within the catchment of the wetland. Mann-Kendall trend test was used to determine whether temperature and rainfall patterns show a significant trend between 1952 and 2006. Results showed that there is a significant increase in mean maximum temperatures at Alheit station ( $\mathrm{p}=0.024, \alpha=0.05)$, while mean annual rainfall amounts were shown to be declining though not statistically significant (Alheit, $p=0.250, \alpha=0.05$; Chivhu $p=0.903, \alpha=0.05$ and Buhera, $p=0.661, \alpha=0.05)$. It was observed that the significant increases in daily maximum air temperatures in an era of declining precipitation and land use changes are major factors in the drying up of Mutubuki wetland.
\end{abstract}

Key Words: Wetland drying, Mann-Kendall trend test, climate change, Mutubuki

\section{Introduction}

Wetlands are areas that are periodically or continuously inundated by shallow water or have saturated soils where plant growth and other biological activities are adapted to the wet conditions (Owen et al., 1995). Wetlands are known as mapani or vleis in Zimbabwe and as dambos in eastern and central Africa (Whitlow, 1985). In Zimbabwe, they cover approximately 1.28 million hectares of land in which $25 \%$ is in communal areas (Whitlow, 1985; Owen et al., 1995).

Many studies have indicated that wetland systems are one of the most vulnerable ecosystems to climate change, over use and degradation (Vourltis and Oechel, 1997; Burkeet, 2000; Zhang et al., 2001; Deng et al., 2003). It has been estimated that more than $50 \%$ of the original global extent of wetlands have been degraded or destroyed by land-use practices like overgrazing, over burning, development pressures like drainage modification, land reclamation and by exotic invasive vegetation or animals (Dugan, 1993; Mulamoottil et al., 1996; Mitsch and Gosselink, 2000).

Urban agriculture and water resource developments still threaten many wetlands, with other threats coming from the possible negative effects of global climate change on wetland structure and function (Burkeet, 
2000). Zimbabwe is now faced with a serious problem of wetland decline, degradation and even total loss yet they are important to local communities because they supply water for drinking, irrigation, domestic purposes (Owen et al., 1995). Wetlands also have hydro-ecological functions like maintaining ecosystem integrity, groundwater recharge and discharge and flood flow alteration (Bullock, 1992; Mitsch and Gosselink, 2000). Climatic and geomorphic conditions are the major driving factors of wetland formation, evolvement, and even disappearance (Mortsch, 1998; Deng et al., 2003). The sensitivity of wetlands to climate change and variability is one of important issues for research. For this reason, this study selected the analysis of climate change signatures on micro-catchments as a means of understanding drying up of wetlands.

Previous studies on wetlands in Zimbabwe have been mostly emphasised on their contributions to agriculture, ecology, biology, and hydrology (Acres et al., 1985; Owen et al., 1995). These studies mainly analysed the wetland's potential use in agriculture, form and structure as well as classification, geology of the wetlands, erosion of the wetlands and their contribution to stream flow (Whitlow, 1985; McFarlane, 1989; Owen et al., 1995). A limited number have tried to analyse wetland-catchment interactions (Acres et al., 1985, McFarlane, 1989; Bullock, 1992), while a paucity of information exists on the persistence of wetlands under changing climatic scenarios, especially at a micro-catchment level (Owen et al., 1995). Thus, this paper is aimed at investigating the impacts of long term rainfall and temperature patterns on Mutubuki wetland in Gutu District of Zimbabwe. Specifically we determined if trends in the patterns of rainfall and temperature can be used to explain the loss of moisture on Mutubuki wetland. Results of this study will assist in our understanding some of the factors that are leading to wetland degradation and loss.

\section{Study Area}

Mutubuki wetland is located in the southeastern part of Gutu district, Zimbabwe and covers an area of $59328 \mathrm{~m}^{2}$ (Figure 1). It is located on the Devure sub-catchment which covers $345 \mathrm{~km}^{2}$ and the Mutubuki microcatchment which covers $32 \mathrm{~km}^{2}$. The wetland occupies a very small area $(0.18 \%)$ of the Mutubuki micro-catchment. It is used by the local Chingombe community to provide drinking water for households, watering their livestock and irrigating their community garden, which is an important source of nutrition and income especially during drought years (Chikodzi et al., 2012). The Mutubuki area is dominated by degraded and fragmented miombo shrublands and receives on average about $500 \mathrm{~mm}$ of rainfall per annum, while the average potential evapotranspiration ranges between 1200 and 1800 $\mathrm{mm}$ (Stiltz and Weyel, 2006). The area is semi arid, with an aridity index of between 02-0.5 (UNCCD, 2012). 


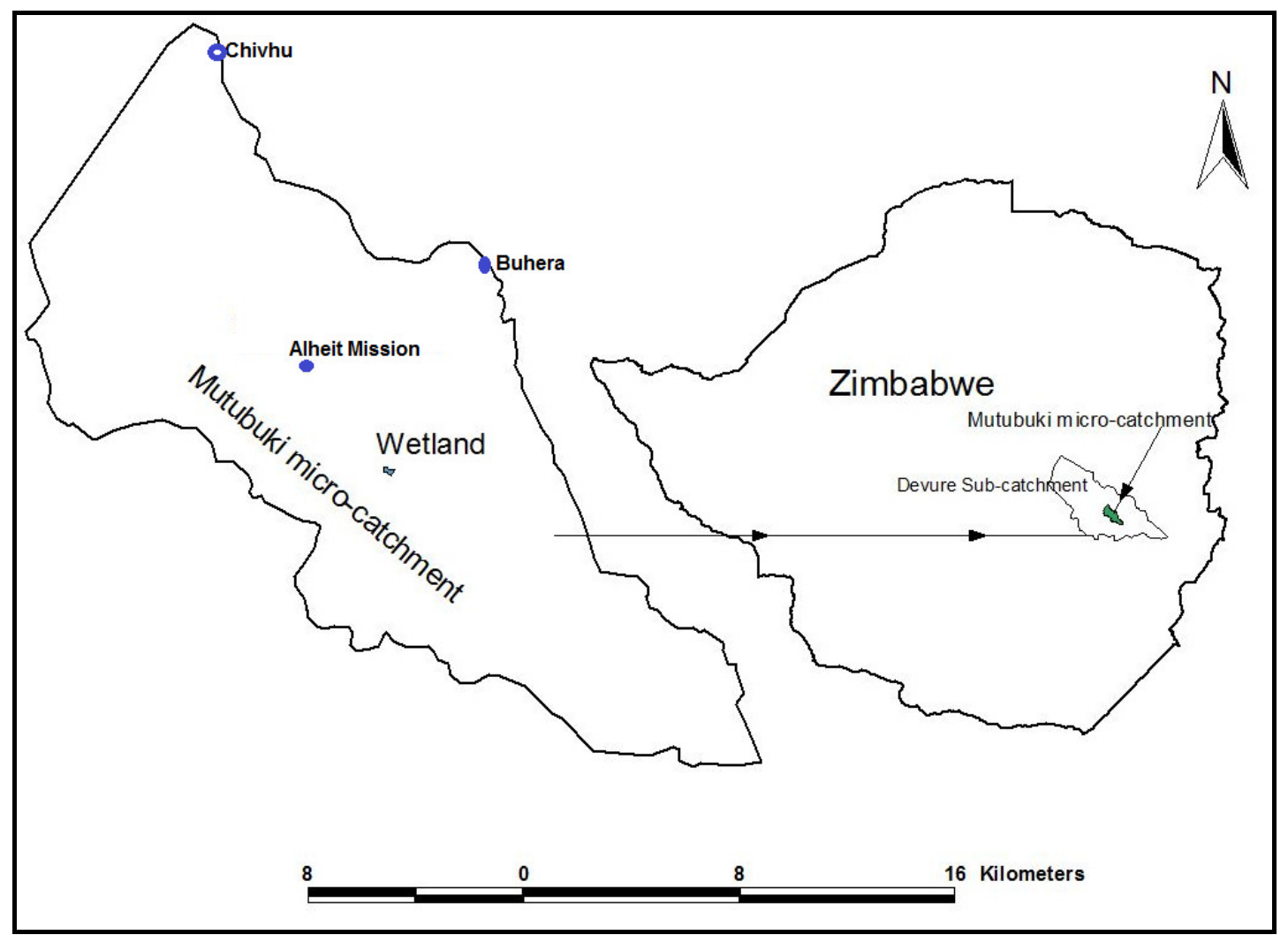

Figure 1: Location of the study area in Zimbabwe, as well as the weather stations used.

The climate of the area is mainly driven by unreliable and extremely variable rainfall with a $39 \%$ coefficient of variability and unbalanced distribution (Stiltz and Weyel, 2006). On average, about $56 \%$ of total annual amount is received during the first half of the rainy season between late October and mid February with pronounced inter annual variations, prolonged mid-season dry spells and erratic distribution that often lead to severe drought and total crop failures (Sengayi, 1991).

The geology of the micro-catchment consists of mainly young intrusive granite rocks, older gneiss complex rocks and dolerite intrusions, while the wetland is situated on an area close to the point of intersection of the young intrusive granite and the older gneiss complex rocks. Young intrusive granite rocks cover mostly the lower catchment of the wetland and a narrow belt sandwiched with an older gneiss complex on the upper catchment of the wetland (Chikodzi et al., 2012).

Soils on the micro-catchment are predominantly coarse-grained sandy loams ranging in depth from shallow to deep with low organic and mineral nutrients, negligible proportions of clay and silt fractions, poor water retention capacity and friable characteristics that make them susceptible to erosion (Sengayi, 1991; Hamandawana et al., 2005).

The Mutubuki micro-catchment area is $100 \%$ communal land dominated by the communal land tenure system. It characterised by increasing population density (30 people $/ \mathrm{km}^{2}$ ) which has negatively impacted on the environment in the form of increased erosion, deforestation, decline of grazing resources and extension of arable land into areas unsuitable for intensive utilization initiating general environmental deterioration (Hamandawana et al., 2005). In 
2007 and for the first time, the wetland dried up and since then it has been supplying water to the community only during the wet season (November - April), and a few months afterwards (Chikodzi et al., 2012). The two streams from the wetland now flow only during the wet season and dry up as soon as rainfall ceases.

\section{Materials and Methods \\ Rainfall and Temperature Data}

Mean maximum temperature data for Alheit station which span from 1952-2003 was used in the study. It was derived from maximum daily air temperatures, averaged over a year. Mean maximum temperature data was used instead of other temperature indicators like mean daily evapotranspiration because all the weather stations in the area have the capacity to measure it and data was readily available. Monthly rainfall data that spans from 1950-2006 for stations Alheit, Chivhu and Buhera were also used in the study. Both the temperature and the rainfall data were obtained from the Meteorological Services Department of Zimbabwe. The Mean maximum temperature and rainfall data were used to determine if trends were present in their time series and also determined further if the trends were of statistical significance. All the station data used in the study has gaps from 2006 to 2014. This is due to the prohibitive costs that the Meteorological Services Department of Zimbabwe place on the data.

\section{Data analysis}

The time series data was first subjected to distribution tests using the KolmogorovSmirnov test in statistical package for social scientists (SPSS) in order to determine how well the data satisfies assumptions of parametric or non-parametric statistical analysis methods. Studies show that, unless the assumption of normal distribution for parametric statistics is met, it is generally advisable to use nonparametric tests
(Lettenmaier, 1976, Hirsch et al., 1993). Non-parametric statistical analysis methods were therefore used in the study.

\section{Auto-correlation and Pre-whitening}

Auto-correlation refers to the correlation of a time series with its own past and future values. Geophysical time series are frequently auto-correlated because of inertia or carryover processes in the physical system. It therefore complicates the application of statistical tests by reducing the number of independent observations thereby increasing the chances of detecting significant trends even if they are absent and vice versa (Hamed and Rao,1998). Pre-whitening is the process of removing unwanted autocorrelations from time series data, prior to the analysis of interest.

Before the data was run in a MannKendall test, it was first tested for serial correlation in a statistical package Paleontological Statistics (PAST) Version 3.0. If autocorrelation was detected, the data would then be pre-whitened in PAST 3.0 using the Auto-Regressive Integrated Moving Average (ARIMA) model (Hamed and Rao, 1998). The model performs time series forecasting and smoothening technique that projects the future values of a series based entirely on its own inertia. ARIMA modeling takes into account trends, seasonality, cycles, errors and non-stationary aspects of a data set when making forecasts. It reduces residuals to white noise in the time series hence removing the possibility of finding a significant trend in the Mann-Kendall test when actually there is no trend (Von Storch, 1995). A detailed explanation of the ARIMA model can be found elsewhere (Von Storch, 1995; Hamed and Rao, 1998).

The Mann-Kendall Trend test was used to determine if there was a significant change in rainfall and temperature patterns over time. The Mann-Kendall test is a non-parametric test for the detection of trend in time series data. The test was used because it is simple, 
robust, can cope with missing values, and seasonality and values below detection limit (Dietz and Kileen; 1981; Hirsch et al., 1993). The software used for performing the statistical Mann-Kendall test is an add-in of Microsoft excel, XLSTAT 2013. The null hypothesis which states that there is no significant trend was then tested at $95 \%$ confidence level for temperature and precipitation data. In addition, linear trend lines were plotted for each station using Microsoft Excel 2007.

Random field visits were also carried out on the wetland and its micro catchment. The main objective was to observe how the moisture regime of the wetland changes during the different seasons of the year and also to administer 30 quantitative questionnaires to local villagers. In the absence of historical measured data on groundwater levels on the wetland and discharge from the nearby streams, the moisture regime of the wetland was reconstructed using local villagers' knowledge. Reconstruction of the moisture regime of the wetland was important for us to determine the rate at which it dried up and to see if it has any links with changes in the climatic condition of the area. The 30 respondents used in the reconstruction of the moisture regime were carefully selected on the basis of their age (only those over 60 years were deemed to be suitable) and of those over 60 years only those who demonstrated the required level of perceptiveness responded to the questions between 27 January to November 30, 2012. In the reconstruct respondents were asked to give a score out of 10 of moisture level on the wetland over a 10 year interval from 1960-2010. The scores were then entered into SPSS and depicted graphically. During the same period, interviews with key informants, namely the local chief, Ward Councillor, Agricultural extension officer, were also carried out.

\section{Results}

Table 1 summarises the results of the distribution test and their interpretation. Normality tests done using the KolmogorovSmirnov test on both rainfall and temperature data show that data from all the stations was not normally distributed.

Table 1: Normality Tests for the climatic data used in the study

\begin{tabular}{llll}
\hline Variable & P-Value & $\alpha$ & Decision \\
\hline $\begin{array}{l}\text { Alheit } \\
\text { temperature }\end{array}$ & .001 & 0.05 & Data significantly deviates from a normal distribution \\
Alheit rainfall & .000 & 0.05 & Data significantly deviate from a normal distribution \\
Buhera rainfall & .003 & 0.05 & Data significantly deviate from a normal distribution \\
Chivhu rainfall & .000 & 0.05 & Data significantly deviate from a normal distribution \\
\hline
\end{tabular}

Autocorrelation tests performed in Past statistic for both temperature and rainfall data from all the stations used showed that the data had no serial correlation (figure 4) hence the data was free from white noise. Figure 2 shows the autocorrelation function (ACF) graphs for all the time series data sets used in the study at $95 \%$ confidence level. None of the ACF were statistically significant hence was no special need to pre-whiten the data before running the Mann- Kendall test. 
Analysis of Climate Change Signatures on Micro-catchments................CHIKODZI \& MUTOWO
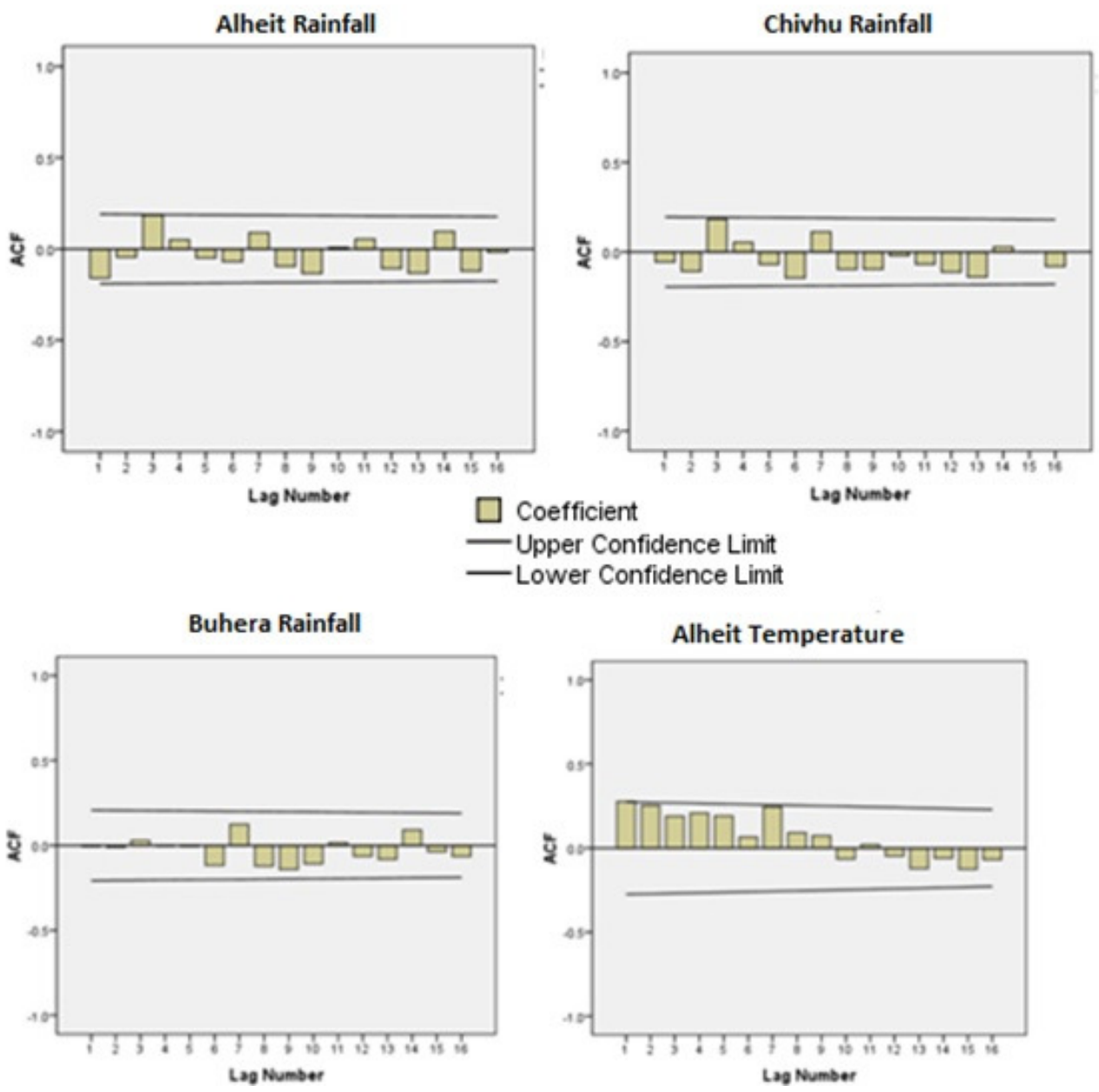

Figure 2: Autocorrelation ACF graphs for time series data used at 95\% confidence level

Figure 3 shows the pattern of mean maximum temperatures for Alheit station between 1952 and 2001. Temperatures on the station show an increasing trend as shown by the positive trend line and its equation.

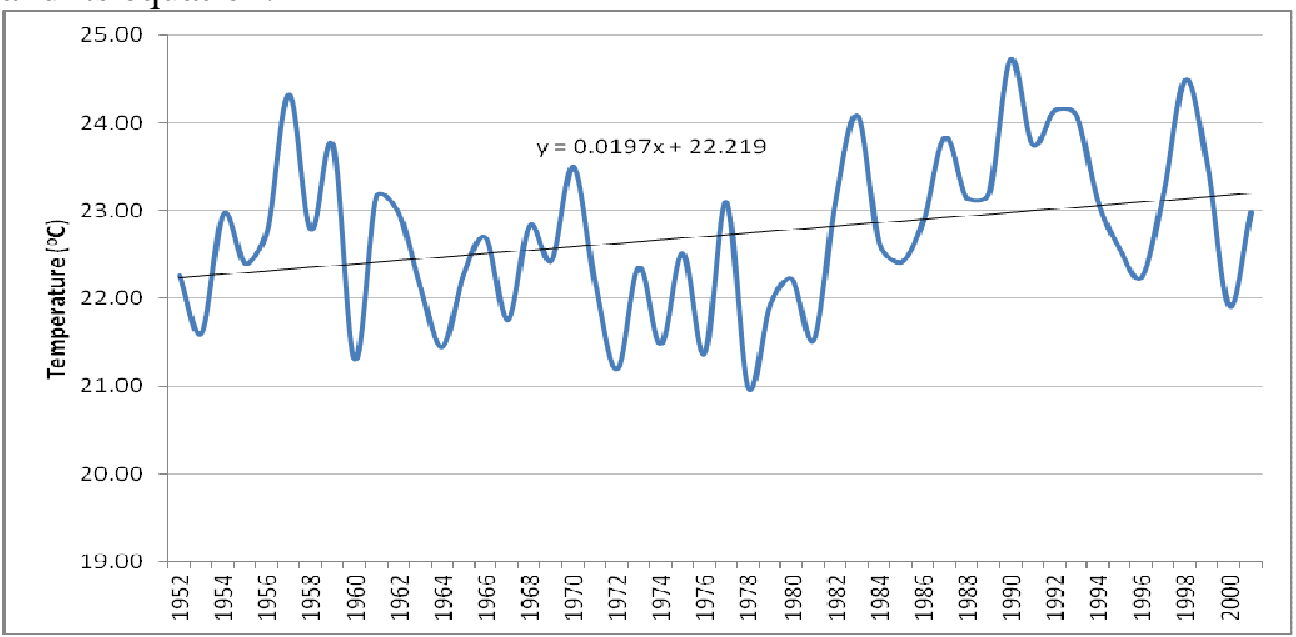

Figure 3: The trend of mean maximum temperatures at Alheit station between 1952 and 2001. The graph shows a significant increase in the mean maximum temperature. 
The Mann-Kendall trend test run showed that the increase in maximum temperatures was statistically significant $(p=0.024, \alpha=0.05)$. Using the normal approximation to the distribution of the average Kendall tau, the risk of rejecting the null hypothesis while it is true is $1.13 \%$.

Figure 4 shows the trend of mean annual rainfall for Alheit, Buhera and Chivhu stations between 1923/24 and 2003/04 seasons. The graph shows an overall decline in rainfall totals, though they are not significant (table1).

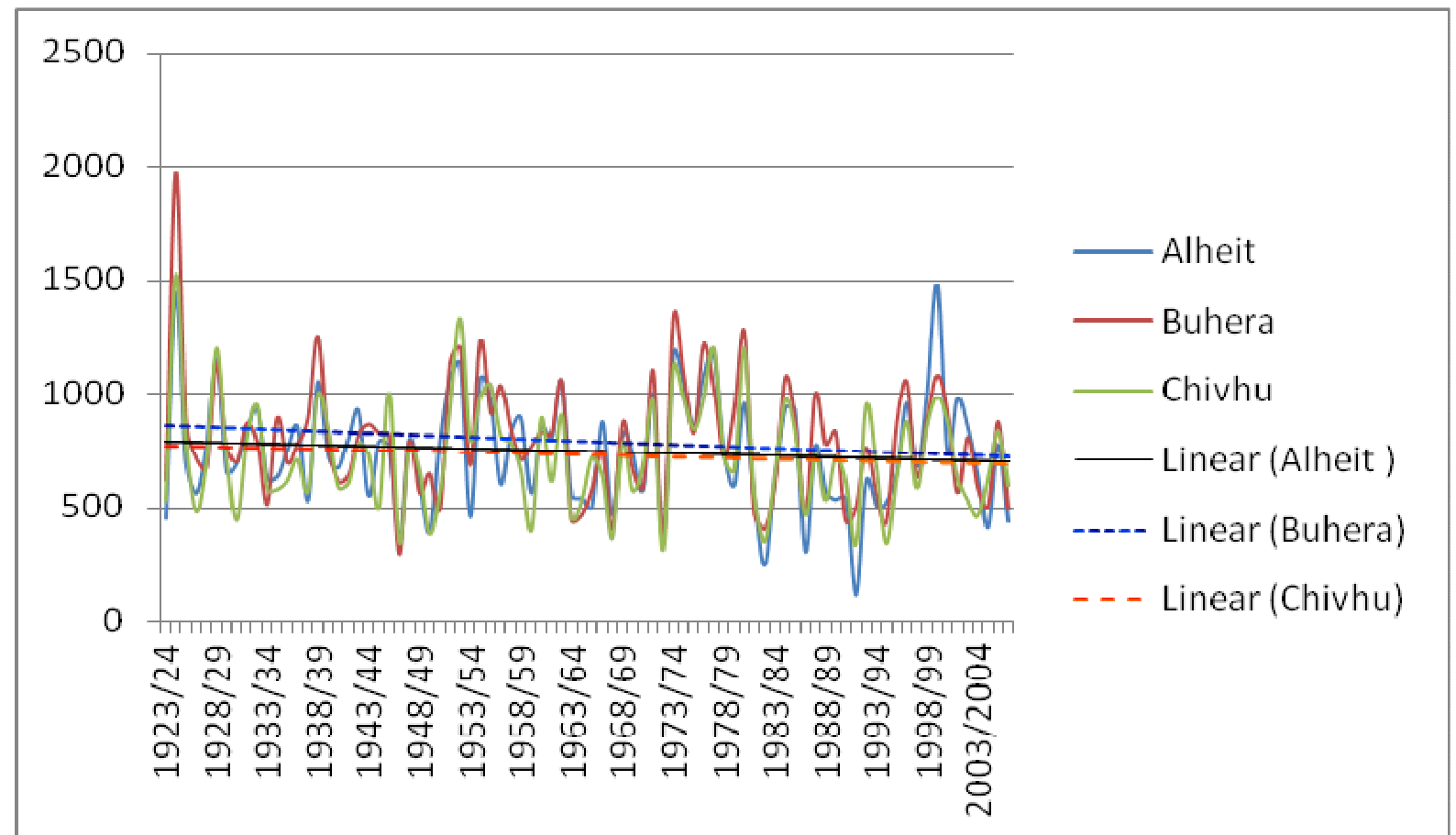

Figure 4: The trend of mean annual rainfall for and stations between 1923/24 and 2003/04 seasons

Table 2 shows that there is no significant change in annual rainfall totals on Mutubuki wetland micro-catchment and the surrounding areas. However, it should be noted that annual total rainfalls for the stations show decreasing trends in rainfall.

Table 2: Mann-Kendall test results and interpretation for rainfall stations

\begin{tabular}{llll}
\hline Rainfall Station & P-Value & $\mathrm{H}_{0}$ Decision & Rainfall Trend Description \\
\hline Alheit Mission & 0.250 & retained & Declining but not significant \\
Buhera & 0.661 & retained & Declining but not significant \\
Chivhu & 0.903 & retained & Declining but not significant \\
\hline
\end{tabular}

Figure 5 shows the scores $(0-10)$ given by questionnaire respondents as they rated the moisture regimes of Mutubuki wetland during the decades between 1960 and 2010. A score of 10 means very high incidences of moisture, with surface water on the wetland lasting all year round, while a score of 0 means very low moisture, with no surface water even during the wet season. The year 1960, in this case, is the baseline for status and trends reports. 


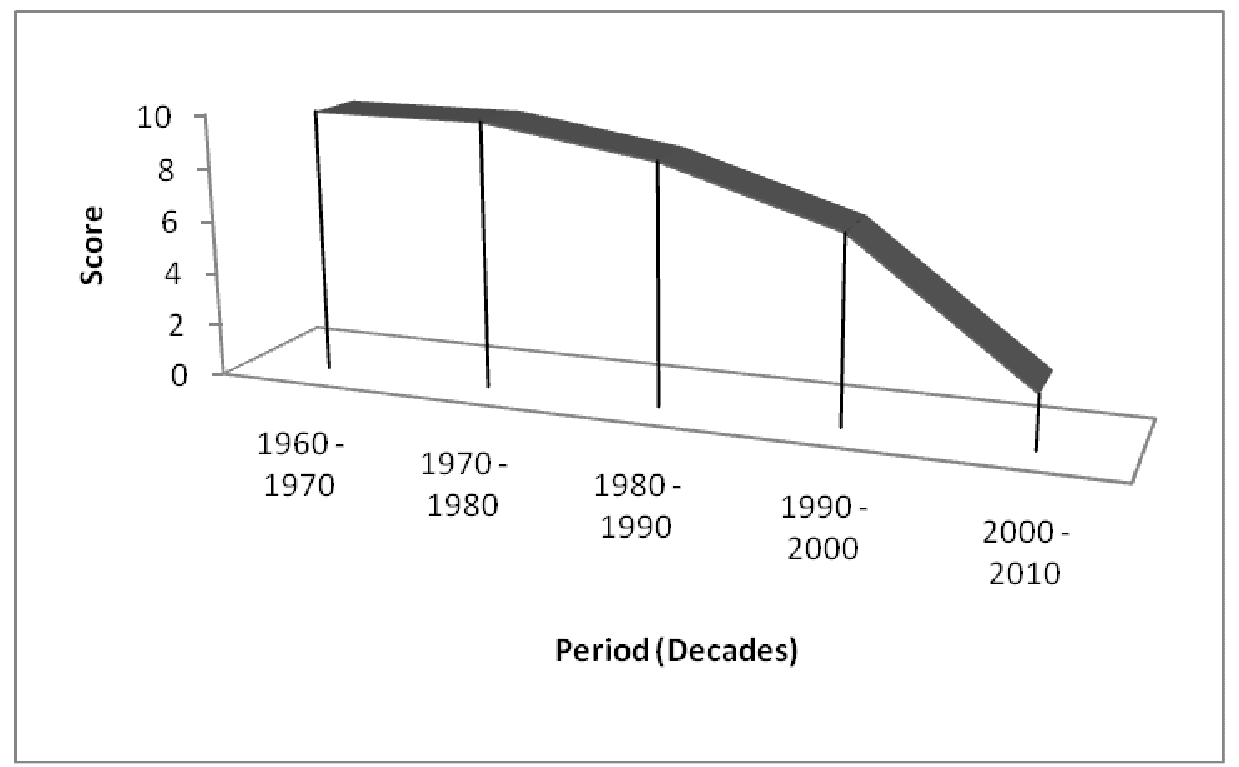

Figure 5: Moisture Regime Trend in the Wetland

Figure 5 shows the moisture on the wetland started dropping gently in the 1980s followed by drastic declines in the 1990s and 2000s. About $65.4 \%$ of the questionnaire respondents confirmed the above, described the drying up of the wetland as having becoming serious around 2007.

\section{Discussion}

The long term changes in climatic parameters noted in Mutubuki has also been noted elsewhere and are predicted to make Zimbabwe, especially the south-eastern parts warmer and drier. For example, in their separate studies, Makarau (1995), Unganai, (1996), Mason and Jury (1997) and Simba et al. (2012) found that the decline in precipitation in Zimbabwe, though not statistically significant, has translated into a decline of up to $10 \%$ on average over the period 1900 to 1993. In addition, Simba et al. (2012) found an increase in the number of seasons recording below normal rainfall since 2002. Thus, although the decline in rainfall is not significant, it can be shown that Mutubuki wetland has been increasingly receiving less and less recharge over the years. Although the link between rainfall and wetland recharge is not necessarily this simple since there is a possibility of wetland recharge by lateral groundwater movement from the surrounding catchment, the decline in rainfall over the larger catchment noted at Buhera and Chivhu stations might also lead to the decline in the amount of groundwater moving from other catchments to Mutubuki.

The increase in maximum temperatures noted in the Mutubuki area can potentially in many cases induce an increased evaporation rate by the atmosphere although it must be noted that evaporation is a function of many interacting factors such as wind speed, soil moisture conditions and relative humidity. Bouwer, (2007) and McCarthy, (2001) in separate studies noted that increases in temperatures induce an enhanced evaporative demand which in turn increases the rate of direct water loss from the wetlands. Small changes in actual evaporation can lead to large changes in surface water flows and storage (Bouwer, 2007).

In addition to the increase in maximum mean temperatures, water loss from the wetland is exacerbated by land cover and land use changes on the wetland, its periphery and surrounding interfluves (figure 3a) were most of the recharge most likely occurs (Kimble, 1960; Bell et al., 1987 
McFarlane, 1989; Owen et al., 1995). The random field visits showed that more than half of the $59328 \mathrm{~m}^{2}$ of the wetland is shrubland, while the wetland periphery and interfluve have a combined 4.5 ha of fully matured Eucalyptus camaldulensis plantations. This was a departure from the grassland, with isolated wetland trees and shrubland vegetation that is characteristic of wetlands in the savanna region (Stewart, 1989; Owen et al., 1995). Eucalyptus species are alien to Zimbabwe, and are fast growing woody species whose rate of water abstraction is very high (Wen et al., 2009; Forsyth et al., 2004). Studies done elsewhere recorded up to a three fold increase in evapotranspiration rates in wooded wetlands, compared with those areas without significant amounts of woody species (Kimble, 1960; Bell et al., 1987; Drayton, 1986; Stewart, 1989; Bullock, 1992). Furthermore, evapo-transpiration rates within the wetland and its periphery might have increased due to the presence of irrigated gardens. Two wells on the core of the wetland that are close to two metres deep are used for watering the nearby 2 hectare community garden, where an estimated 1296 000 litres per year was used by the 30 families that grow vegetables in the wetland.

\section{Conclusions}

The paper was aimed at using long term rainfall and temperature variability as possible factors in explaining the decline of Mutubuki wetland. The drying up of the Mutubuki wetland can be attributed to a combination of increased maximum temperatures and land use changes, all occurring in an episode of declining rainfall. There is therefore a need to manage the land use and land cover changes on wetlands and their recharge zones in order to preserve them.

For rehabilitation of the Mutubuki wetland, we recommend a detailed survey of the most important recharge zones of the wetland where artificial groundwater recharge pits can be constructed to increase the rate of recharge and possible improvement of the moisture regime of the wetland. Also we recommend avoiding replacing indigenous tree species with alien ones like the Eucalyptus camaldulensis in sensitive environments like wetlands as their traits and behaviour in the new environment are not yet fully understood.

We propose that further studies on wetlands should quantify the land cover changes, as well as estimate changes in evapo-transpiration rates emanating from the land cover changes especially the effect of replacing indigenous trees species with alien ones.

\section{References}

Acres, B.D., Rains, A.B., King, R.B., Lawton, R.M., Mitchell, A.J.B. and Rackman, L.J. (1985). African dambos: their distribution, characteristics and use. Zeitschrift für Geomorphologie Supplementbande 52, 62-83.

Bell, M., Faulkner, R., Hotchkiss, P., Lambert, R., Roberts, N. and Windram, A. (1987). The use of dambos in rural development with reference to Zimbabwe. Final Report of ODA Project R3869. London: Overseas Development Administration.

Bouwer, L.B. (2007). Estimates of spatial variation in evaporation using satellitederived surface temperature and a water balance. Wiley InterScience, 670-682.

Bullock, A. (1992). Dambo Hydrology in Southern Africa-review and reassessment. Journal of Hydrology 134:373-396.

Burkeet, J.K. (2000). Climate Change: Potential Impacts and Interactions in Wetlands of the United States. Virginia 
Journal of the American Water Resources Association, 36(2): 313-320. Chikodzi, D., Zinhiva, H., Mutowo, G., Ndlovu, S. and Mazambara, P. (2012). Geology and structure of the dryland Mutubuki wetland of Gutu, Zimbabwe. Herald Journal of Geography and Regional Planning, 1(2): 036 - 042.

Deng, W.E., Pan, X., Luan, Z. (2003). Advance in wetland hydrology. Advance in Water Science, 14(4): 521527 (in Chinese).

Dietz, E.J. and Killeen, T.J. (1981). A nonparametric multivariate test for monotone trend with pharmaceutical applications. Journal of the American Statistical Association, 76, 169-174.

Drayton, R.S. (1986.) Dambo hydrology-an application of satellite remote sensing to water resource studies in the third world. In Proceedings of the international symposium on mapping from modern imagery. Edinburgh: International Society for Photogrammetry and Remote Sensing Commission IV and the Remote Sensing Society, 8-12 September 1986, 125-35.

Dugan, P.J. (Ed). (1993). Wetlands in danger. Mitchell Beazley and IUCN (World Conservation Union), London.

Forsyth, G.G., Richardson, D.M., Brown, P.J. and Van Wilgen, B.W. (2004). Rapid assessment of the invasive status of Eucalyptus species in two South African provinces. South African Journal of Science, 100(1): 75-77.

Hamandawana, H., Nkambwe, M., Chanda, R., Eckardt, F. (2005). Population Driven Changes in Land Use in Zimbabwe's Gutu District of Masvingo Province: Some Lessons from Recent History. Applied Geography 25: 248270.

Hamed, K.H. and Rao, A.R. (1998). A modified Mann-Kendall trend test for autocorrelated data. J. Hydrol. 204: 182-196.

Hirsch, R.M., Helsel, D.R., Cohn, T.A. and Gilroy, E. J. (1993). Statistical analysis of hydrologic data. McGraw Hill, New York, p. 1872.

Kimble, G.T. (1960). Tropical Africa, volume 1. New York: The Twentieth Century Fund.

Lettenmaier, D.P. (1976). Detection of trends in water quality data from records with dependent observations. Water Resources Res, 12(5):1037-1046.

Makarau, A. (1995). Intra-seasonal oscillatory models of the southern Africa summer circulation. $\mathrm{PhD} 30$ Thesis, University of Cape Town, South Africa,324 pp, 1995.

Mason, S.J. and Jury, M.R. (1997). Climatic variability and change over southern Africa: a reflection on underlying processes. Prog Phys Geog, 21(1) 2350, 1997.

$\mathrm{M}^{\mathrm{c}}$ carthy, J.J., Canziani, D.F., Leary, N.A., Dokken, D.J. and WHITE, K.S. (2001). Climate change impacts, Adaptation and Vulnerability. Cambridge University Press, Cambridge, UK, and New York, USA. pp: 1032.

$\mathrm{M}^{\mathrm{c}}$ farlane, M.J. (1989).Dambos- Their Characteristics and Geomorphological evolution in parts of Malawi and Zimbabwe with particular reference to the role in the hydrogeological regime of area of African surface. In groundwater Exploration and development in Cydtalline Basement Aquifers 2:Commonwealth Science Publication.

Mitsch, W.J and Gosselink, J.G. (2000). Wetlands (third edition). Wiley, New York: pp 936.

Mortsch, L.D. (1998). Assessing the impact of climate change on the great lakes shoreline wetlands. Climate Change, 40(2):391-416. 
Mulamoottil, G., Warner, B.G. and $\mathrm{M}^{\mathrm{c}}$ bean, E.A. editors (1996). Wetlands: environmental gradients, boundaries, and buffers. Lewis Publishers, New York.

Owen, R., Verbeek, K., Jackson, J. and Steenhuis, T.(eds) (1995). Dambo Farming in Zimbabwe: Water Management, Cropping and Soil potentials for Smallholder Farming in the Wetlands. University of Zimbabwe Publications Harare.

Sengayi, L. (1991). An investigation of the crystalline basement aquifer of Gutu district: South-East Zimbabwe. Unpublished MSc Dissertation, University of London.

Simba, F.M., Chikodzi, D., Murwendo, T. (2012). Climate change scenarios, perceptions and crop production: a case study of Semi-arid Masvingo Province in Zimbabwe. $J$ Earth Sci Climate Change (JESCC), Vol 3 No3.

Stewart, J.B. (1989). Estimation of aerial evaporation from dambos in Zimbabwe using satellite data The Basement Aquifer Research Report 1984-1989. British Geological Survey, 48-59, Wallingford.

Stiltz, D. and Weyel, U. (2006). A model of an ecology oriented agricultural development programme and its attack on rural poverty exemplified in Gutu district. Osanbruk, Toronto.

Unganai, L.S. (1996). Historic and future climatic change in Zimbabwe. Climate Res, 6: 137-145.
United Nations Convention To Combat Desertification. (2012). Global Dry Lands

http://wwwunccdint/Lists/SiteDocumen tLibrary/Publications/Desertifi cationENpdf (Accessed 5 February 2013).

Von Storch, H. (1995). Misuses of statistical analysis in climate research In: Analysis of Climate Variability: Applications of Statistical Techniques. Springer-Verlag, Berlin, Germany.

Vourltis, G.L., Oechel, W.C. (1997). Landscape-scale CO2, H2O vapor and energy flux of moist-wet coastal tundra ecosystem over two growing seasons. Journal of Ecology, 85: 575-590.

Wen, L., Ling, J., Saintilan, N. and Rogers. K. (2009). An investigation of the hydrological requirements of River Red Gum (Eucalyptus camaldulensis) Forest, using Classification and Regression Tree modelling. Ecohydrol, 2: 143-155 doi: 101002/eco46 (Accessed 5 November 2012).

Whitlow, J.R (1988). Degradation of Wetlands Influence of Human Factors on Erosion Land Degradation in Zimbabwe. Report prepared by the Department of Natural Resources.

Zhang, S., Zhang, B., Wan, G. (2001). Study on the relationship between distributive variation of wetlands and regional climate change in Sanjiang Plain. Advance in Earth Science, 6(6): 836841 (in Chinese). 